\title{
Research on the Construction and Application of MOOC Under the Background of Informatization
}

\author{
$\mathrm{Li} \mathrm{Li}^{* 1}$, Shi Yumin ${ }^{1}$, Zhou Wei ${ }^{1}$, Wang Jiongkun ${ }^{1}$, Li Kun ${ }^{1}$, Wang Xiaoyan ${ }^{1}$ \\ ${ }^{I}$ Naval Aviation University Qingdao Branch, Qingdao, China \\ *qdxqlixia@163.com
}

\begin{abstract}
As a product of the integration of information technology and modern education, MOOC plays an important role in the teaching reform of colleges and universities. Taking the course of aviation equipment storage business as an example, this paper introduces the achievements and experience of course construction under the background of information from the aspects of course design, course production, teaching application and course innovation, so as to provide reference for the construction of MOOCS of the same type of courses.
\end{abstract}

Keywords: aviation equipment, $M O O C$, course construction, teaching reform

\section{INTRODUCTION}

MOOC (Massive Open Online Course) is a large scale open online course. The emergence and development of MOOC has brought great impact on contemporary education, which reflects the influence of using modern educational technology on course reform in colleges and universities. The informatization and intellectualization of military academy's vocational education is an irreversible trend. The future classroom must be the effective combination of intelligent teaching and autonomous learning under the internet. MOOC is an innovative teaching mode, which can show advanced teaching ideas, unique teaching methods and fruitful teaching results, and realize the sharing and popularization of high quality teaching resources. As the main core course of aviation equipment major, aviation equipment storage business management has complex contents and rich knowledge. It is of great significance to carry out MOOC construction for innovating teaching mode and improving teaching effect. ${ }^{[1-3]}$

\section{MOOC COURSE DESIGN}

\subsection{Target Location}

"Aviation Equipment Storage Business Management" course is a science to study the theory and practical activities of aviation maintenance equipment storage in the warehouse. When selecting the content, it should establish the war orientation, insist on teaching war for war, according to the needs of improving the post holding ability of officers and soldiers in the army, and focus on the whole process of quantity management and quality management of aviation equipment in the warehouse, systematically describe the contents of each link management methods, guide the practice of aviation material storage management, promote the construction of military equipment support capability, and comprehensively improve the storage business management ability of officers and soldiers.

\subsection{Frame Structure}

The course structure is divided into four knowledge modules, including the basic knowledge of aviation equipment storage, aviation equipment storage operation management, aviation equipment storage mould control and aviation equipment storage environment management, etc. The aviation equipment storage operation management module is the core content of this course (see Fig. 1).The course focuses on cultivating the management ability of aviation equipment storage business, with basic theory as the support, technical methods as the core, and operation skills as the foothold, comprehensively learning and mastering the relevant theories of aviation equipment storage business management, getting familiar with the basic business of aviation equipment warehouse, and implementing peacetime and wartime aviation equipment storage activities by using various warehouse operation management technologies and methods, so as to form and improve the quality of aviation equipment ability to manage the warehousing business . 


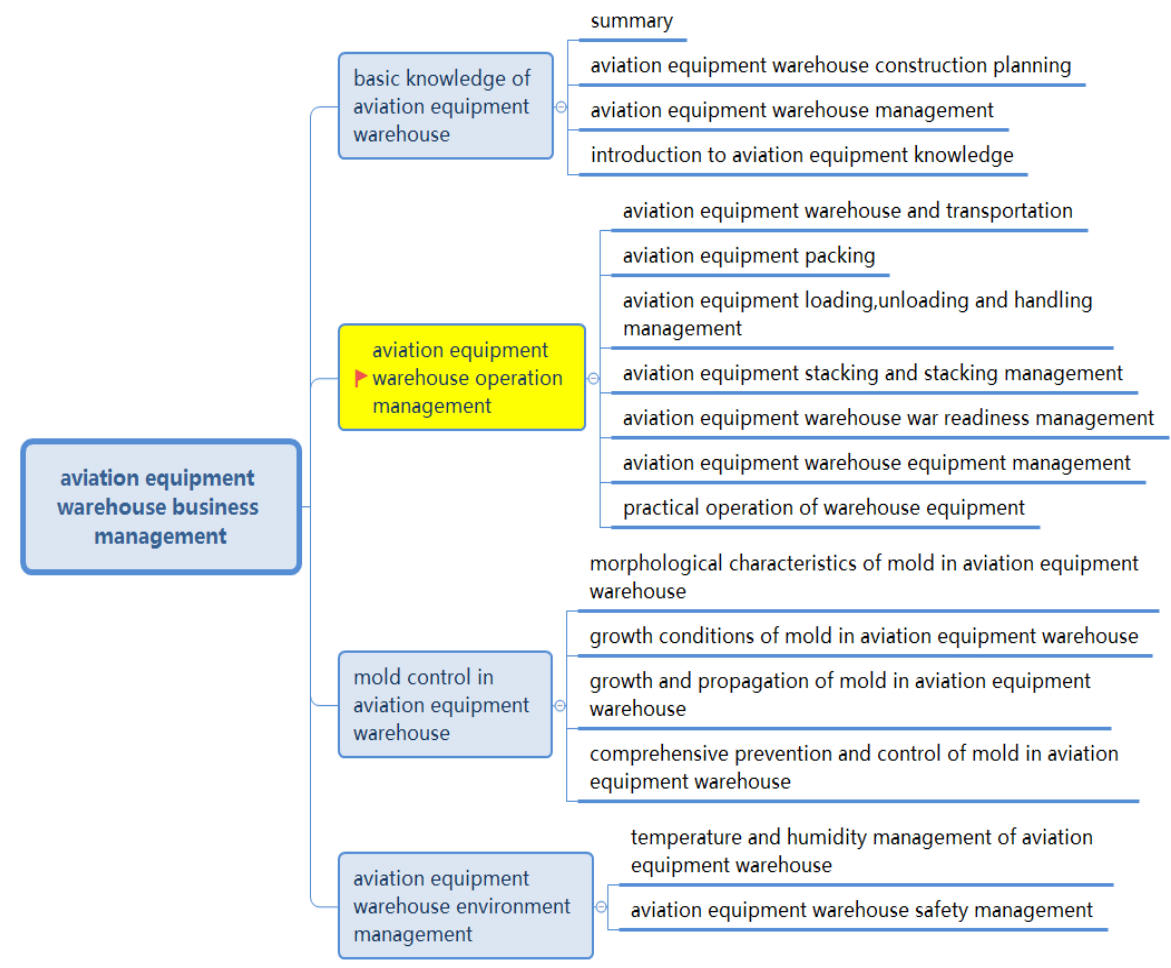

Fig. 1 Knowledge structure of aviation equipment storage business management course

\section{MOOC COURSE MAKING}

\subsection{Teaching Conception}

The online course has obvious characteristics. Each video is short and pithy, perfectly presenting the content of knowledge points. The length of 5-15 minutes of video is in line with the cognitive characteristics and thinking habits of military officers and soldiers. The advanced teaching concept, reasonable integration of pictures, videos and animations, richly and vividly showing the teaching content of the course. Case teaching is closely combined, properly used, innovative, interesting.

\subsection{Video Production}

The course video is well produced, friendly and friendly in design, clean and tidy in picture, bright and harmonious in color, and well used in animation. The shooting adopts the medium range positioning frontal shooting, with novel forms of expression, focusing on practicality, interest and attraction; text, pictures, animation, video and other media materials are closely related to the teaching content. Multimedia courseware is accurate in content, standard in expression, reasonable in design, exquisite in production, and interactive in text, chart, video, animation and other media, with reasonable performance, proper collocation and strong visibility (as shown in Fig. 2 to Fig. 3). In the process of teaching, the teachers are full of spirit, clear thinking, accurate expression, thorough explanation, outstanding key points, vivid language, clear expression, easy to understand, with strong appeal and artistry ${ }^{[4]}$.

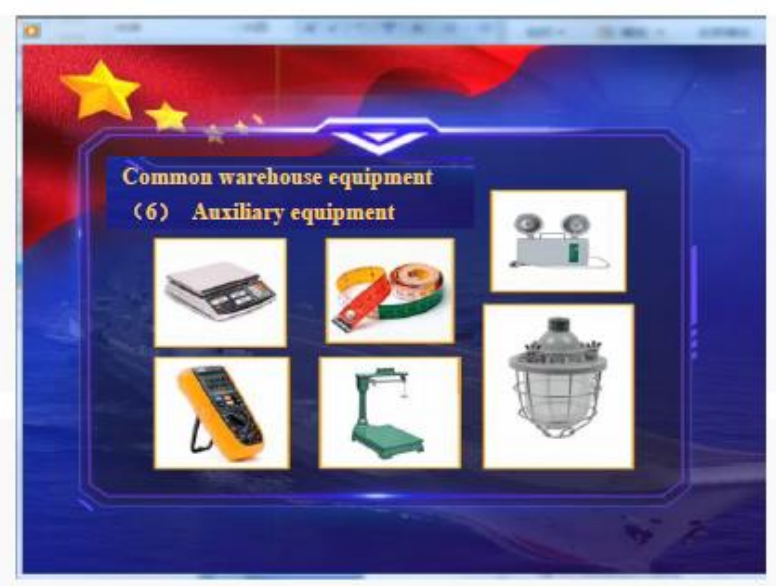

Fig. 2 Course picture screenshot

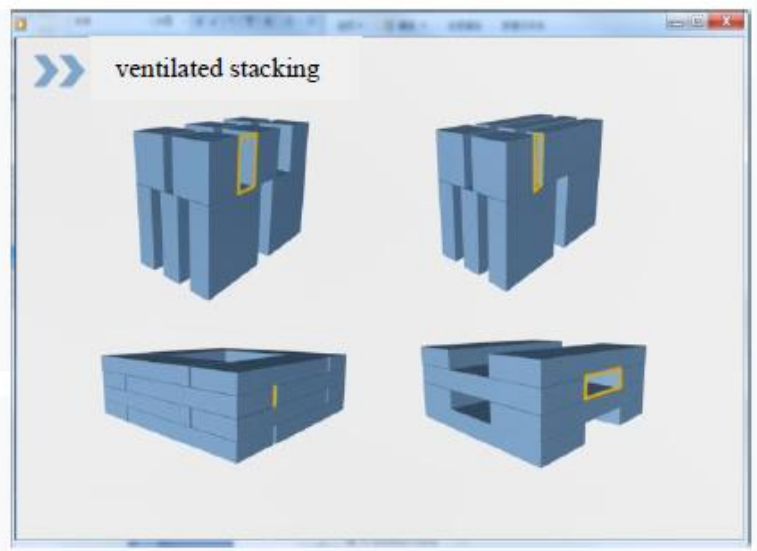

Fig. 3 Course animation screenshot 


\section{APPLICATION OF MOOCS IN TEACHING}

\subsection{Course Announcement}

The course team issued the course announcement in time. The information about the class opening, homework, examination, class ending, providing important information, organizing important seminars and other activities were released through the course announcement, so that the students can accurately grasp the learning status of the course.

\subsection{Interactive Communication}

According to the requirements of the course, the online teaching plan is formulated and strictly implemented. A special person is assigned to help answer questions online. In the course discussion area and discussion area, regular posts are posted to organize discussion activities, and answers and guidance are given on the course platform in the form of question answering, topic discussion, homework evaluation and examination guidance. At the same time, the course group actively carried out offline teaching services, and successively went to several military aviation equipment units to preach MOOC course learning, and conducted on-site teaching guidance. At ordinary times, we mainly adopt the online and offline teaching mode, such as telephone answering, online communication answering, centralized teaching and examination, to conduct real-time communication and discussion with the students. The enthusiasm of the students has improved significantly, and the number of registered students has gradually increased.

\subsection{Course Assessment}

The number of test questions in the course is reasonable, the key and difficult points are prominent, and the difficulty is moderate, which fully meets the needs of students' usual and final examination. Through self-test, students can find weak links, so as to give play to the advantages of MOOC learning and watch videos repeatedly to consolidate and improve their knowledge. The teaching team took the initiative to design students' homework, and made clear that the proportion of course assessment was 20 points for video learning, 40 points for classroom test and 40 points for final examination. At the same time, a new management module homework module is added to the learning platform. According to the students' learning situation, the homework is arranged in the homework area, the starting and ending time of homework are defined, and the evaluation is organized in time. The comprehensive analysis of homework answers and comments and guidance are carried out to consolidate knowledge and strengthen the application function. During the opening period, the platform is open for examination regularly, and each unit organizes the course examination. During the non opening period, the platform organizes an examination once a month. ${ }^{[5-7]}$

\section{MOOC COURSE INNOVATION}

\subsection{Content Innovation - Combat Oriented}

In the content of the course, we fully consider what talents the army needs, and we always adhere to the guidance of actual combat. We integrate a large number of actual military cases into each knowledge point, so that the students can use their brains, think actively, and improve their ability to analyze and solve problems. At the same time, we add the chapter of wartime aviation equipment reserve management to explain the wartime aviation equipment reserve in detail and vividly. The special requirements and methods of storage equipment management truly realize the teaching war and research war, so that students can draw inferences from one instance, understand all things thoroughly, and improve their post ability through effective learning.

\subsection{Video Innovation-role Transformation}

In the video shooting, in order to fully show the seamless connection between the trainees in school and the army post, under the careful guidance of the teachers, a number of sergeant students also actively participate in the MOOC construction of the chapter "warehouse equipment practical operation" of the course, which runs through the whole process of "knowledge selection content design - script writing - video shooting - post editing", so as to make the trainees truly have just experienced the feeling of a teacher, and achieved the goal of applying what I have learned, which reflects my ability to perform my duties. The rapid employment of the trainees after graduation has also been highly recognized by the military employers.

\subsection{Interactive Innovation- Take Various Measures Simultaneously}

The course team not only completed the MOOC construction task with high standard in the case of tight time and heavy tasks, but also attached great importance to the follow-up management of the course, actively carried out the daily maintenance of the course, actively participated in the communication in the discussion area seriously replied to the questions raised by the students, and initiated discussions on the key and difficult contents of the course, so that the students could gather in the cloud and improve together. At the same time, combined with the opportunity to carry out tasks in the army, the course group took the initiative to answer questions and solve doubts for the army officers and soldiers through face-to-face teaching and telephone communication 
online and offline, so as to attract more students to participate in the study of MOOCS.

\section{CONCLUSION}

With the rapid development of the information age, MOOC has brought new teaching ideas and innovative teaching mode to educators. Only by renewing ideas, reforming and innovating, can MOOC play a real role.

\section{REFERENCES}

[1] Shao Yuanchun, et al. Reflections on Teaching Reform in Colleges and Universities triggered by "MOOC" wave [J]. Education and Teaching Forum, 2019,12 (3): 128-129.

[2] Kou Peiyu. Some Reflections on the Popularity of "MOOC" [J]. Forest Teaching, 2015, 215 (2): 3-4.

[3] Li Yajie, Liu Dapeng, Hong Yaoliang. Exploration and Research of MOOC in Environmental Engineering Theory Teaching [J]. Education and Teaching Forum, 2018,(29): 277-278.

[4] Zeng Xiaojie. The Rise of MOOC in American Universities Challenges Traditional Higher Education [J]. Comparative Education Research, 2014 ,(7): 32-40.

[5] Ren Hongtao. On the Opportunities and Challenges of "Environmental Law" Classroom Teaching under the Background of "MOOC" Wave [J]. Journal of Mudanjiang Institute of Education, 2017 (4): 63-66.

[6] Tu Xuan, et al. Design and Construction of "Microbiology" MOOC in Local Colleges and Universities under Smart Campus [J]. Agricultural Products Processing, 2019, (9): 108-111.

[7] Zhu lanbao, et al. Practice of MOOCS Construction in Introduction to Environmental Protection [J]. Anhui Agronomy Bulletin, 2019, 25 (15): 147-149. 